\title{
NON-TRADITIONAL TREATMENTS FOR ENDOMETRITIS IN MARES
}

\author{
J. BUCZKOWSKA ${ }^{1}$, R. KOZDROWSKI ${ }^{1}$, M. SIKORA ${ }^{1}$, M. DZIĘCIOŁ ${ }^{1} \&$ A. MATUSZ ${ }^{2}$ \\ ${ }^{1}$ Department of Reproduction and Clinic of Farm Animals, Faculty of Veterinary \\ Medicine, University of Environmental and Life Sciences, Wroclaw, Poland; \\ ${ }^{2}$ Weterynaria Dobrego Dnia, Dobrodzien, Poland
}

\section{Summary}

Buczkowska, J., R. Kozdrowski, M. Sikora, M. Dzięcioł \& A. Matusz, 2015. Non-traditional treatments for endometritis in mares. Bulg. J. Vet. Med., 18, No. 4, 285-293.

Routine treatment for persistent mating-induced endometritis is directed at enhancing the clearance of accumulated fluid from the uterus and includes the use of ecbolic agents (oxytocin, prostaglandin $F_{2 a}$ ) which may be used alone or in combination with large-volume uterine lavage and administering antimicrobials if infection is diagnosed. However, traditional therapies are not always effective in resolving chronic uterine inflammation or infections. Treatment failure may be caused by uterine exudates, inspissated mucus or biofilm produced by some bacteria and yeast. Exudate can interfere with antibiotic penetration, whereas biofilm can confer antibiotic resistance. The endometrium of mares with delayed uterine clearance or chronic endometritis produces more mucus than reproductively healthy mares. Loss of cilia and abnormal mucus blanket provide areas for bacterial attachment. This review describes new strategies of endometritis treatment that may be added to typical therapy and includes intrauterine mucolytics, chelators, immunomodulators, corticosteroids, nonsteroidal antiinflammatory drugs and others.

Key words: endometritis, mare, treatment

\section{INTRODUCTION}

Endometritis is an important cause of subfertility, affecting approximately $15 \%$ of Thoroughbred mares and resulting in sizable economic losses to the equine industry each year (Troedsson, 1999). In the survey of veterinarians in equine practice in the United States, endometritis was ranked third in importance behind colic and respiratory tract disease (Traub-Dargatz et al., 1991). Failure to remove bacteria, spermatozoa and inflammatory exu- date post-breeding may lead to inflammation of endometrium. Moreover, the factors which underlie susceptibility to endometritis are: defects in genital anatomy, impaired myometrial contractions, impaired immune defense, overproduction of mucus and inadequate lymphatic drainage, abnormal mucociliary clearance and cervical function (Watson, 2000; LeBlanc \& Causey, 2009; LeBlanc, 2010). Uterine inflammation has been proposed as a 
mechanism for impaired myometrial contractility and accumulation of inflammatory products in the uterine lumen (Troedsson et al., 1993; Troedsson, 1999). Neutrophils entering the uterine lumen are the first line of immune defense against invading bacteria. Their migration from the blood is enhanced by chemotactic factors present in uterine fluid which are increased after introduction of infection and inflammation into the uterus (Troedsson, 1999; Watson, 2000). Impaired and reduced myometrial activity will, together with dysfunctional opsonisation, result in impaired phagocytosis of pathogens. Breakdown of uterine physical clearance mechanisms is believed to play an important role in susceptibility to persistent endometritis (Troedsson, 1999). Concentrations of immunoglobulins in uterine secretion in susceptible mares are similar, or even elevated compared to those of resistant mares (Troedsson, 1999).

To detect endometritis the following techniques can be used: clinical examinations including rectal palpation, ultrasonography, cytological, bacteriological and histopathological examination. Findings of uterine fluid, vaginitis, vaginal discharge, short inter-oestrus intervals, inflammatory uterine cytology, positive uterine culture and positive histopathology confirm the diagnosis (LeBlanc \& Causey, 2009; LeBlanc, 2010). However, in subclinical cases, there are no signs like above but excessive oedema post-mating and white lines between endometrial folds on ultrasound may occur (LeBlanc \& Causey, 2009).

Physical clearance can be hindered by anatomical abnormalities or degenerative changes. Moreover, different bacteria express different virulent factors and have different modes of evading the immune response. Some bacteria such as Escheri- chia coli tenaciously adhere to epithelial surfaces, preventing their physical removal. Others such as streptococci stimulate the production of inflammatory exudates, interfering with neutrophil phagocytosis. Moreover, some microorganisms secrete a biofilm that supports growth and maintenance of pathogens. Biofilms provide inherent resistance to antibiotics and both cellular and humoral immune defences resulting in persistent chronic infections even after prolonged antibiotic treatment (Costerton et al., 1995; LeBlanc, 2010). Traditional therapy (post-breeding uterine lavage, oxytocin and intrauterine antibiotics) is not always sufficient. The goals of successful therapy are correcting the defects in uterine defence, neutralising virulent bacteria and controlling postbreeding inflammation (LeBlanc, 2010). Supporting treatment may be added to essential therapy to modulate the immunological uterine response or penetrate biofilm. Additional therapy includes systemic antibiotics, mucolytics: dimethyl sulfoxide (DMSO), kerosene and N-acetylcysteine (NAC), intrauterine chelators: ethylene diaminetetraacetic acid-tromethamine (EDTA-Tris), immunomodulators (cell wall extracts of Mycobacterium phlei and Propionibacterium acnes), corticosteroids (prednisolone, dexamethasone), systemic nonsteroidal anti-inflammatory drugs (NSAIDs) and others (Liu \& Troedsson, 2008; LeBlanc \& Causey, 2009; LeBlanc, 2009; 2010).

\section{MUCOLYTIC AGENTS}

Failure of the treatment may be due to degradation of antibiotic in uterine exudates or biofilm production by microorganisms (LeBlanc \& Causey, 2009). Biofilm is a mucoid substance produced by bacteria and yeast as adaptation to the envi- 
ronment of mares' uterus and expresses an increased resistance to antimicrobial agents (Costerton et al., 1995; LeBlanc \& Causey, 2009; LeBlanc, 2010). Pathogens that produce biofilm are: Pseudomonas aeruginosa, Staphylococcus epidermidis, E. coli, E. cloacae and a number of yeasts and fungi (Costerton et al., 1995; LeBlanc \& Causey, 2009; LeBlanc, 2010). Older, pluriparous barren mares that have anatomical defects more commonly suffer from endometritis, caused by above mentioned microorganisms, than young, fertile mares (Costerton et al., 1995; LeBlanc \& Causey, 2009; LeBlanc, 2010). These infections can be difficult to treat and the typical 3-5 days therapy is unsuccessful. Biofilm confers antibiotic resistance contributing to treatment failure (Costerton et al., 1995; LeBlanc \& Causey, 2009; LeBlanc, 2010). It is suggested to add mucolytic agents, such as DMSO, kerosene and NAC to irrigation fluids to clear exudate, mucus or biofilm (LeBlanc, 2008; LeBlanc \& Causey, 2009; LeBlanc, 2010). In their research Ley et al. (1989) have compared, among other things, therapeutic effect of $0.9 \% \mathrm{NaCl}$ and $30 \%$ DMSO. The mares in oestrus were chosen to flushing of uterus by $60 \mathrm{~mL} 0.9 \% \mathrm{NaCl}$ (control group) or flushing by $60 \mathrm{~mL} \mathrm{30 \%}$ DMSO. Authors mentioned above showed that barren mares infused with a $30 \%$ solution of DMSO after breeding tended to have higher pregnancy rates than mares infused with saline. Moreover, intrauterine DMSO therapy resulted in a significant improvement in histopathological classification of endometrium (e.g. reduction of inflammatory infiltration and periglandular fibrosis) in 18 of 27 mares. On the contrary, only 2 of 18 barren mares improved after saline treatment. Some clinicians recommended the infusion of kerosene into the uterus of mares suffering from chronic Gram-negative, yeast or fungal infection. They suggested that this therapy improves pregnancy rates (LeBlanc \& Causey, 2009). Bracher et al. (1991) administered $50 \mathrm{~mL}$ kerosene into the uterus in 26 mares with pathological endometrial changes, caused inflammation, oedema and production of a serumlike exudate. Five out of 10 mares classified with grade II according to the Kenney scale and 6/11 - with grade III, carried foals until term and foaled. Normally, expected pregnancy rate in mares with grade III according to Kenney is $<10 \%$ and after kerosene therapy it was higher (close to 50\%). Until now, the mechanism by which kerosene improves pregnancy rates is not known. The authors observed 'activation' of endometrial glands and suggested that this might be responsible for the higher pregnancy rate. Kerosene reduced mucus and exudate through destruction of uterine epithelium and cleared secretions in dilated, cystic glands. Half of the examinated mares exhibited necrosis of luminal epithelium. Breeding in the next cycle might have resulted in pregnancy because the uterus could rapidly regenerate epithelial cells. Nevertheless, using kerosene is controversial and needs further research (LeBlanc \& Causey, 2009).

Additionally, the research of NAC used in removing dense uterine secretions was performed in infertile mares. Excessive mucus secretion by the endometrium may contribute to infertility, because of delaying the passage of sperm to the oviduct, resulting in uterine fluid accumulation and may be irritating to the epithelium of endometrium (LeBlanc \& Causey, 2009). Gores-Lindholm et al. (2013) administered intrauterinely $3.3 \%$ NAC solution $(30 \mathrm{~mL}$ of $20 \%$ NAC added to $150 \mathrm{~mL}$ of sterile saline) $24-36 \mathrm{~h}$ before 
breeding in infertile mares who produced a lot of mucus in the uterus. After breeding, uterus flushing with solutio Ringeri was performed, oxytocin was administered and ceftiofur was given if needed. After these procedures $77 \%$ pregnancy rate was obtained. Taking into consideration the above results, the authors demonstrate that NAC improves pregnancy rates in mares with higher mucus secretions in uterus. Furthermore, 3.3\% NAC was administered intrauterinely in healthy mares and no changes in endometrium, only reduction of mucus amount were observed (Gores-Lindholm et al., 2013). N-acetylocysteine is a mucolytic agent which reduces viscosity of mucus by breaking the cross-linking disulphide bridges between mucin polymers. Moreover, NAC has antioxidant, anti-inflammatory and probably antibacterial properties (Zuin et al., 2005; Gores-Lindholm et al., 2013). However, further investigations are necessary to confirm NAC impact on pregnancy rates in mares with a history of infertility (LeBlanc \& Causey, 2009).

\section{CHELATING COMPOUNDS}

Other compounds which have to be taken into consideration are chelating agents used in human and small animals medicine as a therapy to improve antibiotic penetration in biofilm-producing organisms. One such agent, EDTA-Tris, has been effective in chronic cystitis in women; chronic otitis externa, chronic dermatitis and recurrent cystitis in dogs; fungal keratitis and chronic Pseudomonas endometritis in mares (Wooley et al., 1984; Youngquist et al., 1984; Farca et al., 1993; Fumuso et al., 2007; LeBlanc \& Causey, 2009). Wooley et al. (1984) performed an intrauterine infusion of $250 \mathrm{~mL}$ EDTA-Tris, $\mathrm{pH} 8$, causing an inflamma- tory response, as well as we get after saline infusion into the uterus. Additionally, the studies accomplished in vitro showed that addition of EDTA-Tris to gentamicin improved killing of $P$. aeruginosa one thousand times than treatment with gentamicin only. The volume of the buffered chelating agents solution used for infusion will vary with the size of the uterus and ranging from 200-500 mL, because agents must come in direct contact with the bacterial cell wall to kill the organism (LeBlanc, 2010). The chelating agent binds to the bacteria resulting in cell death and accumulation of debris and uterus should be lavaged within $12 \mathrm{~h}$ to remove it. It is recommended to infuse 250-500 mL Tris-EDTA (day 1), next lavage the solution out within $24 \mathrm{~h}$ and examine the efflux. If the efflux is cloudy, EDTA-Tris is infused into the uterus again on day 2. Next on day 3 antibiotics are started and continued daily for a minimum 5 days (LeBlanc, 2010).

\section{IMMUNOMODULATORS \& STEROIDS}

To reduce developing post-breeding induced endometritis, the immunomodulators may be used. Treatment with immunostimulatory agents has been reported to improve pregnancy rates, although the mechanism of action remains speculative (LeBlanc \& Causey, 2009). Two immunostimulants are labelled and marked for use in horses. One is a cell wall extract of Mycobacterium phlei (Mycobacterial cell wall extract, MCWE; Settle, Bioniche Animal Health, Bogard, GA, USA), that has been approved as an adjunctive treatment in mares with uterine infection caused by Streptococcus equi subsp. zooepidemicus (Fumuso et al., 2007; Rogan et al., 2007; Liu \& Troedsson, 2008; LeBlanc \& Causey, 2009) and E. coli (Chris- 
toffersen et al., 2012). It was suggested that this immunostimulator modulates endometrial cytokines (increases the level of proinflammatory cytokines) in susceptible mares (Rohrbach et al., 2007; Liu \& Troedsson, 2008; LeBlanc \& Causey, 2009). The second immunostimulator is Propionibacterium acnes (EqStim; Neogen Corp, Lexington, KY, USA). It is used as an adjunct treatment for horses with equine respiratory disease complex. The use of $P$. acnes in addition to traditional treatment in infertile mares with chronic endometritis has yielded positive results. Namely, a higher pregnancy and live foal rates were obtained than in mares treated only with conventional treatments (Rohrbach et al., 2007; Liu \& Troedsson, 2008; LeBlanc \& Causey, 2009). P. acnes is reported to have immunostimulant properties, however, the mechanism by which immunity is induced is incompletely understood. The effect on the immune cascade includes release of cytokines that increase activity in the general immune defense system after $P$. acnes administration (Cox, 1988).

In addition, there is evidence that the judicious use of steroids may increase pregnancy rates in mares with endometritis (Fumuso et al., 2007; Rohrbach et al., 2007; Bucca et al., 2008; Papa et al., 2008; Vandaele et al., 2010). Glucocorticoid therapy is a common medication to manage inflammatory diseases because of potent anti-inflammatory and immunosuppressive properties. A single injection of dexamethasone administered during first hour after breeding $(0.1 \mathrm{mg} / \mathrm{kg})$ combined with routine post-breeding therapies results in increased pregnancy rates in mares with a history of fluid accumulation (Bucca et al., 2008). Decreased uterine oedema, decreased intrauterine fluid and an increase in uterine fluid clarity in trea- ted mares were observed. Christoffersen et al. (2012), observed that when dexamethasone was used in mares with experimental induced $E$. coli endometritis as an adjunctive treatment, fluid accumulation rarely occured. Oral administration of prednisolone $(0.1 \mathrm{mg} / \mathrm{kg})$ at 12-hour intervals for 4 days beginning $48 \mathrm{~h}$ before breeding, also improved pregnancy rates in mares susceptible to fluid accumulation (Papa et al., 2008). In contrast, administration of dexamethasone (10 or $20 \mathrm{mg}$ i.m.) 6-12 h after insemination did not cause good effects on pregnancy rate in mares (Vandaele et al., 2010). By reducing number and chemotaxis of neutrophils recruited into the uterus post-mating, steroidal drugs may diminish the severity and length of the inflammatory response. It is worth noticing that steroids should be used carefully because misuse of these drugs in mares with bacterial endometritis may exacerbate the infection (LeBlanc \& Causey, 2009; LeBlanc, 2010).

\section{NSAIDS}

There are also reports on the use of NSAIDs in the treatment of chronical endometritis in mares. Koblischke et al. (2008) showed that NSAIDs inhibit the migration of neutrophils and $\mathrm{COX} 2$ expression in the endometrium in the luteal phase in recipient mares after the embryo transfer. Therefore, the research on the use of NSAIDs in the treatment of endometritis was performed. For this purpose, vedaprofen was administered twice daily (starting dose of $2 \mathrm{mg} / \mathrm{kg}$, followed by $1 \mathrm{mg} / \mathrm{kg}$ ), starting one day before the first insemination, and ending one day after ovulation in mares (Rojer \& Aurich, 2010). Mares also received oxytocin three times per day (20 IU). There was no effect on the amount of neutrophils 
in the endometrium in the treated mares. However, a higher pregnancy rate was obtained (Rojer \& Aurich, 2010) but as the effect of NSAIDs on the immune response in the endometrium of mares is not known, further studies are needed in this regard.

\section{OTHER TREATMENTS}

Autologous/heterologous plasma has been used intrauterinely by some authors (Liu $\&$ Troedsson, 2008). The exogenous plasma contains opsonins which enhance phagocytosis of bacteria and it could be useful in treatment of endometritis. Plasma is thought to increase the efficiency of the mare's cellular uterine defense mechanisms (LeBlanc \& McKinnon, 2011). However, the efficacy of colostrum are still not known and because of the effort of collection and storage, intrauterine plasma is no longer widely used (Liu \& Troedsson, 2008; LeBlanc \& Causey, 2009). Neves et al. (2007) performed the research using leukocytes in mares with experimentally evoked endometritis. Fresh leukocytes administration into the uterus caused rapidly evacuation of bacteria from uterus than frozen and lysed leukocytes (Neves et al., 2007). There are no data about practical application of this therapy in the field.

In their study, Couto \& Hughes (1985) infused intrauterinely bacteria-free filtrate of Streptococcus zooepidemicus in BrainHeart Infusion Broth in mares. Although the number of mares bred after infusion was limited, many chronically barren mares returned to normal fertility. Streptococcus filtrate is important in clearing up uterine infection by supplying fresh, functionally normal PMNs which eliminate the microorganisms. The intrauterine infusion with streptococcal filtrate might provide an alternative treatment for mares with chronic uterine infections refractory to conventional antimicrobial therapy.

Intrauterine infusions of a variety of solutions have been used to treat infectious endometritis. Antiseptics include iodine, chlorhexidine, hypertonic saline, magnesium sulfate and hydrogen peroxide solution. The clinician should be aware that many of these solutions are strong irritants and can cause damage to the endometrium. Troedsson (2011) does not recommend routine use of these solutions in the uterus. Weak solutions of hydrogen peroxide have been used as treatment for acute endometritis and also appear helpful when exudates has been found in the uterine lumen. After phagocytosis by neutrophils bacteria are destroyed in part by oxidative metabolism, which includes hydrogen peroxide (Wolfsdorf \& Caudle, 2007). In case of fungal endometritis $3 \%$ hydrogen peroxide solution may be added to the saline $(30 \mathrm{~mL}$ hydrogen peroxide in $1 \mathrm{~L}$ of $0.9 \%$ saline) in uterine irrigation to help lift off debris containing fungus which may adhere to the luminal epithelium (Ricketts, 1999). Irrigation with dilute iodine solutions, e.g. $250 \mathrm{~mL} \mathrm{10 \%}$ povidone-iodine in saline solution has been recommended but experience suggests that this may cause quite severe genital inflammation in individual mares and it may be wise to start with a more dilute solution $(0.5 \%$ povidone iodine $)$ and then assess the response before going on (Ricketts, 1999). According to Troedsson (2011) if povidone iodine is used for intrauterine treatment, it should be applied as a very dilute solution $(0.05-0.10 \%)$ in lactated Ringer solution. The effect of magnesium sulphate solution on the equine endometrium has been studied. Treatment mares were infused with magnesium sulphate solution (128 $\mathrm{g}$ in one $\mathrm{L}$ 
of $0.9 \%$ saline). No harmful effects were noted when mares were evaluated on days 1, 7 and 21 after infusion (Dascanio et al., 1998). It should be noted that assessment of the effect of magnesium sulfate on specific uterine pathologies or fertility was not made (Dascanio et al., 1998).

Acupuncture performed before and after breeding also appears to assist in uterine drainage as clinicians report decreased uterine oedema, decreased intrauterine fluid, and increased uterine tone 24 hours after acupuncture treatment (LeBlanc \& McKinnon, 2011). The decrease in the uterine fluid accumulation may be attributable partly to improvement in local circulation and the uterine blood flow as a result of the central inhibition of sympathetic nerve activity (Tangjitjaroen et al., 2009).

In conclusion, depending on the type of pathogen, causing endometritis in mares, there is a different inflammatory response of the uterus. The failure of conventional therapy of antibiotics leads to the development of chronic inflammatory conditions of the endometrium. Some bacteria and fungi colonising the uterus of mares produce biofilm which cause antibiotic resistance. Therefore, mucolytics, chelates, steroids, and NSAIDs have found use in the treatment of endometritis in mares. New methods of treatment of endometritis in mares are promising, so further studies are relevant to their improvement.

\section{ACKNOWLEDGMENTS}

This paper was supported by the grant of the NCN, DEC-2011/01/B/NZ5/04173.

\section{REFERENCES}

Bracher, V., A. Neuschaefer \& W. R. Allen, 1991. The effect of intra-uterine infusion of kerosene on the endometrium of mares. Journal of Reproduction and Fertility. Suppl., 44, 706-707.

Bucca, S., A. Carli, T. Buckley, G. Dolci \& U. Fogarty, 2008. The use of dexamethasone administered to mares at breeding time in the modulation of persistent mating induced endometritis. Theriogenology, $\mathbf{7 0}$, 1093-1100.

Christoffersen, M., E. M. Woodward, A. M. Bojesen, M. R. Petersen, E. L. Squires, H. Lehn-Jensen \& M. H. T. Troedsson, 2012. Effect of immunomodulatory therapy on the endometrial inflammatory response to induced infectious endometritis in susceptible mares. Theriogenology, 78, 9911004.

Costerton, J. W., Z. Lewandowski, D. E. Caldwell, D. R. Korber \& H. M. LappinScott, 1995. Microbial biofilms. Annual Review of Microbiology, 49, 711-745.

Couto, M. A. \& J. P. Hughes, 1985. Intrauterine inoculation of a bacteria-free filtrate of Streptococcus zooepidemicus in clinically normal and infected mares. Journal of Equine Veterinary Science, 2, 81-86.

Cox, W. I., 1988. Examining the immunologic and hematopoietic properties of an immunostimulant. Journal of Veterinary Medici$n e, 6,424-428$.

Dascanio, J. J., N. A. Parker, W. B. Ley, L. D. Warnick \& D. P. Sponenberg, 1998. Magnesium-sulfate intrauterine therapy in the mare. Equine Practice, 20, 10-13.

Farca, A. M., P. Nebbia \& G. Re, 1993. Potentiation of the in vitro activity of some antimicrobial agents against selected Gram-negative bacteria by EDTA-tromethamine. Veterinary Research Coтmunications, 17, 77-84.

Fumuso, E. A., J. Aguilar, S. Giguere, M. Rivulgo, J. Wade \& D. Rogan, 2007. Immune parameters in mares resistant and susceptible to post-breeding endometritis effects of immunomodulation. Veterinary Immunology and Immunopathology, 118, 30-39. 
Gores-Lindholm, A. R., M. LeBlanc, R. Causey, A. Hitchborn, R. A. Fayrer-Hosken, M. Kruger, M. L. Vandenplas, P. Flores \& S. Ahlschwede, 2013. Relationships between intrauterine infusion of $\mathrm{N}$ acetylcysteine, equine endometrial pathology, neutrophil function, post-breeding therapy, and reproductive performance. Theriogenology, 80, 218-227.

Koblischke, P., H. Kindahl, S. Budik, J. Aurich, F. Palm, I. Walter, J. Kolodziejek, N. Nawotny, H-O. Hoppen \& C. Aurich, 2008. Embryo transfer induces a subclinical endometritis in recipient mares which can be prevented by treatment with nonsteroid anti-inflammatory drugs. Theriogenology, 70, 1147-1158.

LeBlanc, M. M., 2008. When to refer an infertile mare to a theriogenologist. Theriogenology, 70, 421-429.

LeBlanc M. M., 2009. The current status of antibiotic use in equine reproduction. Equine Veterinary Education, 21, 156-167.

LeBlanc, M. M., 2010. Advances in the diagnosis and treatment of chronic infectious and post-mating-induced endometritis in the mare. Reproduction in Domestic Animals, 45, 21-27.

LeBlanc, M. M. \& R. C. Causey, 2009. Clinical and subclinical endometritis in the mare: both threats to fertility. Reproduction in Domestic Animals, 44, 10-22.

LeBlanc, M. M. \& A. O. McKinnon, 2011. Breeding the problem mare. In: Equine Reproduction. $2^{\text {nd }}$ edn, eds O. McKinnon, E. L. Squires, W. E. Vaala \& D. D. Varner, Blackwell Publishing Ltd., pp. 2620 2642.

Ley, W. B., J. M. Bowen, D. P. Sponenberg \& P. N. Lessard, 1989. Dimethyl sulfoxide intrauterine therapy in the mare: Effects upon endometrial histological features and biopsy classification. Theriogenology, 32, 263-276.

Liu, I. K. M. \& M. H. T. Troedson, 2008. The diagnosis and treatment of endometritis in the mare: Yesterday and today. Theriogenology, 70, 415-420.
Neves, A. P., A. Keller, C. Rodrigues-Trein, G. Moller, M. I. Mascarenhas-Jobim, L. F. F. Castilho, M. R. de Itapema Cardoso, W. Leibold, H. Zerbe, E. Klug, R. M. Gregory \& R. C. Mattos, 2007. Use of leucocytes as treatment for endometritis in mares experimentally infected with Streptocccus equi subsp. zooepidemicus. Animal Reproduction Science, 97, 314-322.

Papa, F. O., J. A. Jr Dell'aqua, M. A. Alvarenga, C. M. Melo, F. Soares Zahn \& M. D. Lopes, 2008. Use of corticosteroid therapy on the modulation of uterine inflammatory response in mares after artificial insemination with frozen semen. Pferdeheilkunde, 24, 79-82.

Ricketts, S. W., 1999. The treatment of equine endometritis in studfarm practise. Pferdeheilkunde, 15, 588-593.

Rogan, D., E. Fumuso, E. Rodriguez, J. Wade \& F. Sanchez Bruni, 2007. Use of Mycobacterial Cell Wall Extract (MCWE) in susceptible mares to clear experimentally induced endometritis with Streptococcus zooepidemicus. Journal of Equine Veterinary Science, 27, 112-117.

Rohrbach, B. W., P. C. Sheerin, C. K. Cantrell, P. M. Matthews, J. V. Steiner \& L. E. Dodds, 2007. Effect of adjunctive treatment with intravenously administered Propionibacterium acnes on reproductive performance in mares with persistent endometritis. Journal of the American Veterinary Medical Association, 231, 107-113.

Rojer, H. \& C. Aurich, 2010. Treatment of persistent mating-induced endometritis in mares with non-steroid anti-inflammatory drug vedaprofen. Reproduction in Domestic Animals, 45, 458-460.

Tangjitjaroen, W., J. Shmalberg, P. T. Colahan $\&$ H. Xie, 2009. Equine acupuncture research: An update. Journal of Equine Veterinary Science, 9, 698-709.

Traub-Dargatz, J. L., M. D. Galman \& J. L. Voss, 1991. Medical problem of adult horses, as ranked by equine practitioners. Journal of the American Veterinary Medical Association, 198, 1745-1747. 
Troedsson, M. H. T., 1999. Uterine clearance and resistance to persistent endometritis in the mare. Theriogenology, 52, 461-471.

Troedsson, M. H. T., 2011. Endometritis. In: Equine Reproduction, $2^{\text {nd }}$ edn., eds $\mathrm{O}$. McKinnon, E. L. Squires, W. E. Vaala \& D. D. Varner, Blackwell Publishing Ltd., pp. 2608-2619.

Troedsson, M. H. T., I. K. M. Liu, M. Ing, J. Pascoe \& M. Thurmond, 1993. Multiple site electromyography recordings of uterine activity following an intrauterine bacterial challenge in mares susceptible and resistant to chronic uterine infection. Journal of Reproduction and Fertility, 99 , 307-313.

Vandaele, H., P. Daels, S. Piepers \& M. M. LeBlanc, 2010. The effect of post-insemination dexamethasone treatment on pregnancy rates in mares. Animal Reproduction Science, Suppl., 121, 110-112.

Watson, E. D., 2000. Post-breeding endometritis in the mare. Animal Reproduction Science, 60-61, 221-232.

Wolfsdorf, K. \& A. B. Caudle, 2007. Inflammation of the tubular reproductive tract of the mare. In: Current Therapy in Large Animal Theriogenology 2, eds R. S. Youngquist \& W. R. Threlfall, Saunders Elsevier, Philadelphia, pp. 158-167.

Wooley, R. E., M. S. Jones \& E. B. Shotts, 1984. Uptake of antibodies in Gram-nega- tive bacteria exposed to EDTA-Tris Veterinary Microbiology, 10, 57-70.

Youngquist, R.S., T.L. Blanchard, D. Lapin \& W. Klein, 1984. The effects of EDTA-Tris infusion on the equine endometrium. Theriogenology, 22, 593-599.

Zuin, R., A. Palamidese, R. Negrin, L. Catozzo, A. Scarda \& M. Balbinot, 2005. Highdose $\mathrm{N}$-acetylcysteine in patients with exacerbations of chronic obstructive pulmonary disease. Clinical Drug Investigation, 25, 401-408.

Paper received 30.10.2014; accepted for publication 13.03.2015

\section{Correspondence:}

Justyna Buczkowska

Department of Reproduction and

Clinic of Farm Animals

Faculty of Veterinary Medicine,

University of Environmental

and Life Sciences,

Pl. Grunwaldzki 49, 50-366 Wroclaw, Poland, e-mail: justyna.gumienna@up.wroc.pl 